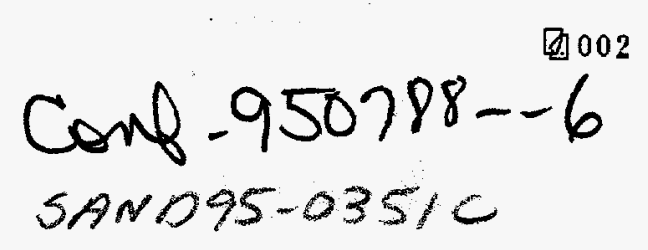

\title{
Models for Predicting Damage Evolution in Metal Matrix Composites Subjected to Cyclic Loading
}

\author{
D. H. Allen, L. D. Hurtado, K. L. E. Helms, and D. C. Lagoudas
}

Center for Mechanics of Composites, Texas A\&M University, Texas, U.S.A.

\section{ABSTRACT}

A thermomcchanical analysis of a continuous fiber metal matrix composite (MMC) subjected to cyclic loading is performed herein. The analysis includes the effects of processing induced residual thermal stresses, matrix inelasticity, and interface cracking. Due to these complexities, the analysis is performed computationally using the finite element method. Matrix inelasticity is modelled with a rate dependent viscoplasticity model. Interface fracture is modelled by the use of a nonlinear interface constitutive model. The problem formulation is summarized, and results are given for a four-ply unidirectional SCS-6/B21S titanium composite under high temperature isothermal mechanical fatigue. Results indicate rate dependent viscoplasticity can be a significant mechanism for dissipating the energy available for damage propagation, thus contributing to improved ductility of the composite. Results also indicate that the model may be useful for inclusion in life prediction methodologies for MMC's.

\section{INTRODUCTION}

Many studies have been reported on the behavior of SiC/Ti alloy metal matrix composites (MMC's). A detailed literature search including research on the most popular SiC/Ti alloy systems is given in a recent publication by Allen et al. [1]. Most recently, a composite system using a metastable Ti alloy called B21S has been investigated because of its superior oxidation and corrosion resistance.

The general characterization of B21S was performed by TIMET Henderson Technical Laboratory including the processability, and resistance to oxidation and corrosion $[2,3,4,5,6,7]$. Wallace et al. [8] studied the oxidation of $321 S$ at high temperatures. Bavarian and coworkers have done further research into the corrosion behavior $[9,10,11]$. Neu [12] has determined the material parameters for B21S for use in a version of the Bodner-Partom model, in order to model its high temperature viscoplastic behavior. In general, in these works B21S was found to have both high specific and elevated temperature strength, good processability, and improved oxidation, corrosion, and creep resistance.

Because of the above mentioned qualities, the B21S alloy was seen to be

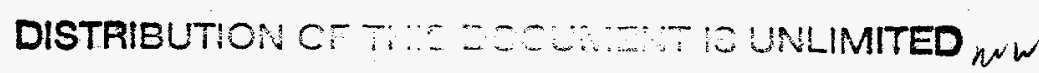

This work was supported by the Uniled States Department of Energy under

Contraci DE-ACn4-94ALR5Dno, 


\section{DISCLAIMER}

This report was prepared as an account of work sponsored by an agency of the United States Government. Neither the United States Government nor any agency thereof, nor any of their employees, makes any warranty, express or implied, or assumes any legal liability or responsibility for the accuracy, completeness, or usefulness of any information, apparatus, product, or process disclosed, or represents that its use would not infringe privately owned rights. Reference herein to any specific commercial product, process, or service by trade name, trademark, manufacturer, or otherwise does not necessarily constitute or imply its endorsement, recommendation, or favoring by the United States Government or any agency thereof. The views and opinions of authors expressed herein do not necessarily state or reflect those of the United States Government or any agency thereof. 


\section{DISCLAIMER}

Portions of this document may be illegible in electronic image products. Images are produced from the best available original document. 
an excellent candidate for matrix material in MMC's and has recently been used as such. Some experimental studies on the behavior of the composite have been performed. The general mechanical property evaluation of the SCS6/321S composite was performed by Cervay [13]. Ghonem et al. [14] have studied the effects of temperature and frequency on fatigue crack growth. Newaz [15] has experimentally evaluated the mechanical response of SCS6/B21S and Sigma/\$21S in compression, and modeled the response using the concentric cylinder model.

Several other researchers have begun modelling various aspects of the behavior of SiC/B21S. Tamin, et al. [16] have investigated a SM1240/3321S compusile using the finite element method (FEM) to determine the stress evolution in bijdging fibers during fatigue crack growth. Tamin, et al. [17] have also modeled the response of this composite using a concentric cylinder model considering both plastic and creep behavior. Ghonem et al. [18] have applied an interactive experimental/mathematical technique to on SCS-6/321, composite. This technique simulates composite behavior and determines the stress states in the composite. Many other recent works on this subject are discussed in reference 1.

\section{FORMULATION}

The problem of interest in this work is modelling the response of a four ply unidirectional B21S MMC subjected to cool down from processing temperature and subsequent isothermal fatigue. This research will include the effects of viscoplasticity in the matrix and fiber-matrix debonding. The temperature is first assumed to be cooled down from a processing temperature of $815^{\circ} \mathrm{C}$ to $482^{\circ} \mathrm{C}$ in a time period of $240 \mathrm{sec}$. Thereafter, the specimen is subjected to isothermal losding with amplitude of $1206 \mathrm{MPa}(r=0.1, \mathrm{f}=0.5 \mathrm{~Hz}$ ). A description of the formulation of the necessary equations used in the analysis of this problem will fallow.

\subsection{Governing Equations}

The displacement vector field $u_{i}\left(x_{k} t\right)$ and the temperature field $T\left(x_{k}, t\right)$ are chosen as the primary field variables. The Cauchy stress tensor $\sigma_{i j}\left(x_{k}, t\right)$ and the infinitesimal strain tensor $\varepsilon_{i j}\left(x_{k}, t\right)$ are chosen as the secondary field variables. The standard range and summation conventions apply to all subscripts in these equations, unless otherwise noted.

(a) Conservation of Momentum

In the absence of body forces and inertial effects, linear momentum is assumed to be satisfied if

$$
\sigma_{\mathrm{ji}, \mathrm{j}}=0
$$

Angular momentum is conserved by imposing symmetry of the stress tensur.

(b) Strain-Displacement Equations 
For infinitesimal displacements, the kinematic relationship becomes

$$
\varepsilon_{i j}=\frac{1}{2}\left(u_{i j}+u_{j, i}\right)
$$

(c) Constitutive Equations

The fiber can be modeled using the isotropic linear thermoelastic constitutive equations given by

$$
\sigma_{i j}=C_{i j k}^{f}\left(\varepsilon_{\mathrm{k} \mid}-\varepsilon_{k j}^{T}\right)
$$

where the superseript $f$ denotes the fiber phase. The tensor $C_{i j k l}^{f}$ is the elastic modulus tensor, and $\varepsilon_{k l}^{T}$ is the thermal eigenstrain.

The matrix can be modeled using a thermoviscoplastic model. The model chosen for this research is a version of Bodner's anisotropic model [19,20], as described in Table I. The Bodner material constants used in this paper are given in Table 1 [19].

\subsection{Finite Element Implementation}

The finite element formulation is a result of all of the above equations being cast into a variational formulation and then discretized. This procedure is detailed in Allen et al. [21]. The thermomechanical code used in this analysis is an in-house code called SADISTIC (Structural Analysis of Damage Induced Stresses in Thermo-Inelastic Composites). This algorithm requires extensive computational requirements due to the time stepping procedure necessary for integrating the viscoplastic constitutive equations.

(a) Boundary Conditions and Meshes

The boundary conditions are shown on the Representative Volume Element (RVE) in Fig. 1. A multiple constraint condition is applied on the right face during cool down by the use of a penalty function as outlined in Cook [22]. Although it may be important to include the effects of spatial thermal gradients [23], the current results assume a spatially homogeneous temperature distribution and generalized plane strain conditions. All elements are constant strain triangles except those at the fiber-matrix interface which are modeled using interface elements $[21,24]$.

\section{RESULTS AND DISCUSSION}

The results of the thermomechanical analysis of the damage evolution in a four-ply unidirectional SCS-6/B21S titanium composite under isothermal. mechanical fatigue are presented and discussed below.

As shown in Fig. 2, the model compares favorably to experimental results for the first few cycles of loading. However, the model does tend to underpredict the composite strains. This may be due to the fact that the model assumes periodicity of the fibers, whereas significant fiber "swimming" is observed in these composites, thus producing local stress concentrations which lead to 
accelerated damage accumulation. Fig. 3, demonstrates the ability of the model to predict accumulation of stresses in the fiber on each successive cycle. It is this history dependent response which must be captured in order to predict component life. Note, however, that for the 49 cycle case shown in Fig. 6 , the code required 20,000 time steps and approximately 2.6 CPU hours on a Power MAC 7100 operating at approximately 13.8 MFLOPS. Therefore, complete life prediction computations will most likely require a super computer.

These preliminary results indicate that both nonlinear viscoplastic matrix behavior and the presence of interface cracking can be incorporated to more accurately predict the damage evolution in MMC's under cyclic loading. The current results suggest that the model may be extendable to predict component life.

\section{ACKNOWLEDGMENT}

The authors gratefully acknowledge the support provided for this research by the Air Force Office of Scientific Research under Grant No. F49620-94-10341.

\section{REFERENCES}

[1]D.H. Allen, M.R. Eggleston, and L.D. Hurtado, to appear in Fracture of Composites, E.S. Armanios, Ed., in Key Engineering Materials series, Trans Tech Publications (1994).

[2]P.R. Smith and W.C. Revelos, Proc. Titanium Matrix Composite Workshop, Orlando, Florida (1992), pp.236-242.

[3]J.S. Grauman and E.E. Mild, Proceedings of the OMAE Conference, Edmonton (June 1992).

[4]P.J. Bania and W.M. Parris, Proceedings of the 7th World Conference on Titanium, San Diego, California (June 1992).

[5]W.M. Parris and P.J. Bania, Proceedings of the 7th World Conference on Titanium, San Diego, California (June 1992).

[6]J.S. Grauman, Proceedings of the 7th World Conference on Titanium, San Diego, California (June 1992).

[7]J.S. Grauman, Proceedings of the 7th World Conference on Titanium, San Diego, California (June 1992).

[8]T.A. Wallace, K.E. Wiedemann, and R.K. Clark, NASA Technical Memorandum 104217 (1992).

[9]B. Bavarian, V. Wahi, G. Canzona, and M. Zamanzadeh, Proceedings of the AEROMAT 93: Advanced Aerospace Materials/ Processes Conference (1993). [10]B. Bavarian, G. Canzona, and M. Zamanzadeh, Proceedings from the CORROSION 93: NACE Annual Conference and Corrosion Show (1993), pp.243/1-243/9.

[11]B. Bavarian and M. Zamanzadeh, Proceedings from the CORROSION 93: NACE Annual Conference and Corrosion Show (1993), pp.284/1-284/10. 
[12]R.W. Neu, Nonisothermal Material Parameters for the Bodner-Partom Model, ASME Winter Annual Meeting, New Orleans (December 1993).

[13]R.R. Cervay, SCS-6//21s and SCS-9/321s Mechanical Property Evaluation, NASP Contractor Report 1165, Wright-Patterson AFB, Ohio (April 1994).

[14]H. Ghonem, Y. Wen, and D. Zheng, Mat. Sci. Eng., Vol.Al61 (1993), pp.4553.

[15]G. Newaz, private correspondence, (1994).

[16]M.N. Tamin, D. Zheng, and H. Ghonem, Proceedings of the ASTM 3rd Symposium on Advances in Fatigue Lifetime Predictive Techniques, Montreal, Quebec, Canada (1994).

[17]M.N. Tamin, D. Zheng, and H. Ghonem, submitted to J. Comp. Tech. Res., (1994).

[18]H. Ghonem, Y. Wen, and D. Zheng, Mat. Sci. Eng., Vol.A177 (1994), pp.125-134.

[19]K.S. Chan, S.R. Bodner, and U.S. Tindholm, Phenomenolgical Modeling of Hardening and Thermal Recovery in Metals, J. Eng. Mat. \& Tech., Vol.110 (1988), pp.1-8.

[20]S.D. Bodner, in Unified Constitutive Equations for Creep and Plasticity, A.K. Miller, Ed., Elsevier Publications, New York (1987).

[21]D.H. Allen, R.H. Jones, and J.G. Boyd, J. Mech. Phys. Solids, Vol.42 No.3 (1994), pp.505-529.

[22]R.D. Cook, D.S. Malkus, and M.E. Plesha, Concepts and Applications of Finite Element Analysis, 3rd Ed., John Wiley \& Sons, New York (1989).

[23]G.S. Jeong, D.H. Allen, and D.C. Lagoudas, Residual Stress Evolution Due to Cool Down in Viscoplastic Metal Matrix Composites, Intnl. J. Solids Struct.,Vol.31 No. 19 (1994), pp.2653-2677.

[24]A. Needleman, J. Appl. Mech.,Vol.54 (1987), pp.525-531.
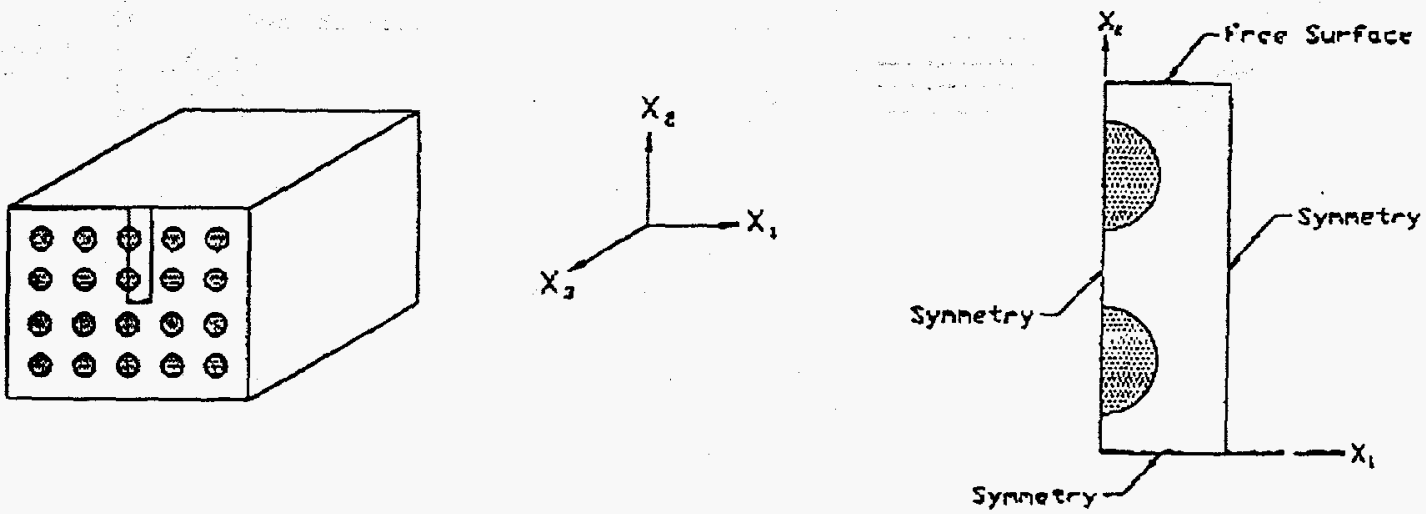

Fig. 1. Depiction of Four-ply Unidirectional Compasite and Unit Cell 


$$
\begin{aligned}
& \sigma_{i j}^{M}=C_{i j k l}^{M}\left(\varepsilon_{k !}^{E}+\varepsilon_{k l}^{I}+\varepsilon_{k l}^{T}\right) \\
& D_{2}^{P}=D_{0}^{2} \exp \left\{-\left[\frac{Z^{2}}{3 J_{2}}\right]^{\mathrm{D}}\right\}, \quad Z=Z_{1}+Z_{D}, \quad J_{2}=\frac{1}{2} \sigma_{i j} \dot{\sigma_{i j}} \\
& \varepsilon \frac{T}{i j}=\lambda \sigma_{i j}^{\prime}, \lambda=\sqrt{\frac{D_{2}^{p}}{J_{2}}}, \quad \sigma_{i j} \equiv \sigma_{i j}-\frac{\sigma_{k k}}{3} \delta_{i j}, \\
& Z_{1}=M_{1}\left(Z_{1}-Z_{I}\right) W_{P}-A_{1} Z_{1} \frac{\left(Z_{1}-Z_{2}\right)^{2}}{Z_{1}}, W_{P}=\sigma_{i j} \varepsilon_{i j}^{l}, Z_{I}(0)=Z_{0} \text {, } \\
& \dot{\beta}_{i j}=M_{2}\left(Z_{3} u_{i j}-\beta_{i j}\right) \dot{W}_{p}-A_{2} Z_{j}\left(\frac{\left(\beta_{k 1} \beta_{k i}\right)^{\frac{1}{2}}}{Z_{1}}\right]^{r_{2}} v_{i j} \\
& Z_{D}=\beta_{i j} u_{i j}, Z_{D}(0)=0, \quad \beta_{i j}(0)=0, \\
& v_{i j}=\frac{\beta_{i j}}{\left(\beta_{k 1} \beta_{k l}\right)^{\frac{1}{2}}} \quad, u_{i j}=\frac{\sigma_{i j}}{\left(\sigma_{k l} \sigma_{k 1}\right)^{\frac{1}{2}}}
\end{aligned}
$$

with material constants: $D_{0}, Z_{0}, Z_{1}, Z_{2}, Z_{3}, M_{1}, M_{2}, A_{1}, A_{2}, r_{1}, r_{2}, n$.

Table I. Bodner's Anisotropic Viscoplastic Model

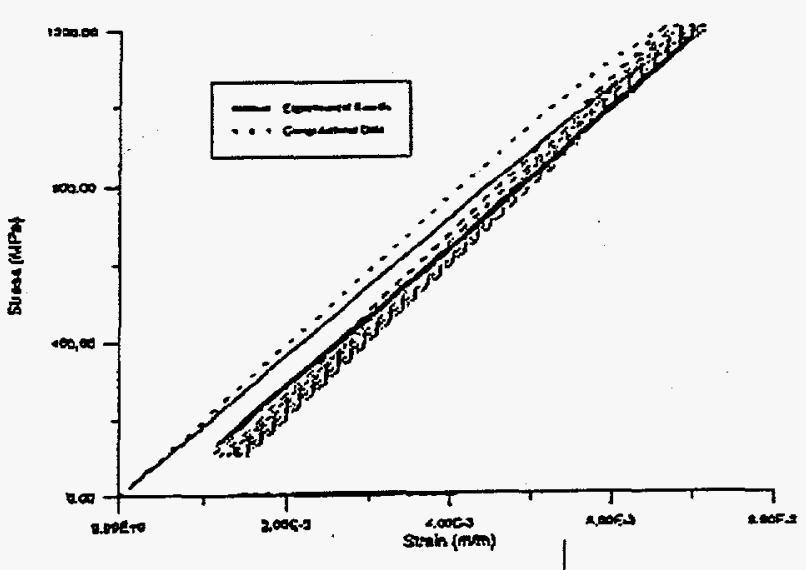

Fig. 2. Comparison of Model to Experiment

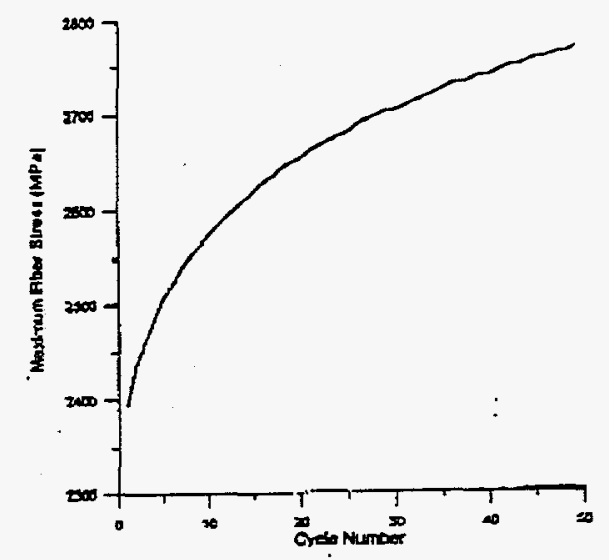

Fig. 3. Predicted Accumulation Fiber Strain vs. Cycle No. 